\title{
MACHINES, MEDICATION, MODULATION: CIRCUITS OF DEPENDENCY AND SELF-CARE IN LAS VEGAS
}

\begin{abstract}
The intensive entertainment infrastructure of Las Vegas is overlaid with a robust therapeutic network for those who become addicted to its technologies. Although the objectives of gambling machines and addiction therapeutics are seemingly at odds - the first work to encourage play, the second to stop it - both gear their interventions around a model of the self as a continuum of behavioral potentials that can be externally modulated. For compulsive gamblers implicated in this circuit of modulation, pharmaceutical drugs that have been prescribed to dampen cravings for machine play sometimes function as intensifiers of its effects. Caught in an intractable play between technologies of harm and technologies of care, recovering gambling addicts are challenged to assemble a technical array through which they can maintain balance; health itself, for these individuals, becomes a state of managed dependency. This essay explores the shifting terms and changing stakes of subjectivity and health in the contemporary United States by way of ethnographic research on compulsive gamblers who live and work in Las Vegas. The analysis draws on interviews with gamblers as well as on observations in local self-help groups, directed group therapy sessions, and chat rooms of Internet recovery Web sites.
\end{abstract}

KEY WORDS: addiction, gambling, pharmaceuticals, technology, the self

TERRY

Terry, a small blue-eyed woman in her early sixties, lives in a ground-floor studio unit in the Archie Grant Projects of North Las Vegas. It's evening and the only light in the apartment comes from the lamp between our two chairs and the television screen in front of us. She smokes 120s, ashing them into a large, black cigarette tray on her lap. Every fiber of the carpeted, curtained apartment is thick with smoke. Terry's nasal oxygen inhaler is held in place by thin plastic tubing that ropes up around her ears and joins beneath her chin. The tubing runs down the folds of her housedress and winds around her feet, then off in the direction of a motorized, gurgling noise that I assume to be a component of her oxygen equipment, humming from an area of cluttered shadows at the other end of the apartment. A large box of medications rests atop a pyramid of three television sets.

"Addiction runs in my family," Terry says. Between drags she catalogues the dependencies of her six children: Her youngest boy is an alcoholic and former drug addict; her oldest daughter is a bingo fanatic who also plays the lottery; another daughter goes from man to man; two other daughters have Culture, Medicine and Psychiatry

(C) 2006 Springer Science +Business Media, Inc.

DOI: 10.1007/s11013-006-9018-y 


\section{N.D. SCHÜLL}

overeating problems; her youngest girl is "multiply addicted"- to crack cocaine, alcohol, abusive men, keno machines, and video poker. "Maybe I have all of these addictions," Terry muses, "just in different degrees."

She drove to Las Vegas from Illinois in 1983 after her doctors recommended a dry, desert climate for her chronic lung disease. She had just acquired an associate's degree in business at junior college with an emphasis in accounting: "What better place than Vegas," she speculated, "to use that degree?" Since moving to the city, Terry has struggled to get her video poker play under control. It doesn't help that the technology "keeps advancing." The machines that accept 20-dollar bills have been particularly exacerbating: "I gamble much faster when I don't have to put the coins in-I don't have to wait for a change girl, I don't have to get up." Not long ago Terry gambled for 36 hours straight; as long as she has money to play, time doesn't matter. "I often gamble money for medications that are absolutely necessary for my survival," she tells me.

Last week I had to pick up a medication at Savon pharmacy. I have no car so I walked there with my new oxygen tank. I forgot my cigarettes and by the time I got there I was so desperate I picked a butt off the ground to smoke. The only place to sit was in front of a poker machine. Just going near that machine was unwise-before I got up I had dropped a 100-dollar bill and I was broke again. I couldn't get the medication I'd come for, couldn't get a cab home, couldn't walk home either, and I was almost out of oxygen. I asked a lady in the parking lot if she could give me a ride home-it turned out I knew her from Gamblers Anonymous. She was oxygen dependent too and went to the same doctor I did.

\section{CIRCUITS}

\section{Circuit:}

1. The complete path between two terminals over which one-way or two-way communications may be provided.

2. An electronic path between two or more points, capable of providing a number of channels.

Compulsive machine gamblers who live in Las Vegas, a group estimated to constitute as high as 6.4 percent of the local population (Volberg 2001:136), are distinguished less by shared socio-economic, racial, or gender characteristics than by a common drive to escape the anxieties and disappointments of their lives through the mechanical repetition offered by gambling technologies (Schüll n.d.). ${ }^{1}$ Carefully designed to promote extended gambling, these technologies have earned the names "electronic morphine" and "the crack cocaine of gambling" (Schüll 2005). They have come to 
dominate the local gambling ecology in Las Vegas, generating 89 percent of casino revenue in gambling establishments that cater to residents and even more when one takes into account the machines in gas stations, pharmacies, and supermarkets (see Figure 1). Compulsive machine gamblers describe their city as an environment of intensified technological stimulation and themselves as particularly susceptible to this stimulation. "It feels dangerous out there," a middle-aged real-estate agent told me: "Certain things could trigger me to play at any moment, I'm not sure what would set me off." The wife of a successful banker prays in parking lots outside of Lucky's grocery store, repeating to herself I have to eat, I have to eat, then hurries past the video poker machines that flank the entranceway. A young single mother, on excursions to buy milk and baby formula, closes her eyes and rushes by the machines. Elements of the environment, she says, "push my buttons and put me in danger of betting." One gambler, a former psychology major, described Las Vegas as a "giant Skinner box."

For those who become compulsively caught in its devices, the city's entertainment infrastructure is overlaid with a robust therapeutic network. Tacked to the wall above a bank of video poker machines in a gas station serving a residential neighborhood, flyers advertise clinics, self-help groups, and other locally available therapies to treat excessive gambling (see Figure 2). The machines themselves bear stickers indicating the 1-800 number for Gamblers Anonymous (GA), a recovery fellowship modeled on Alcoholics Anonymous offering more than 100 meetings per week throughout

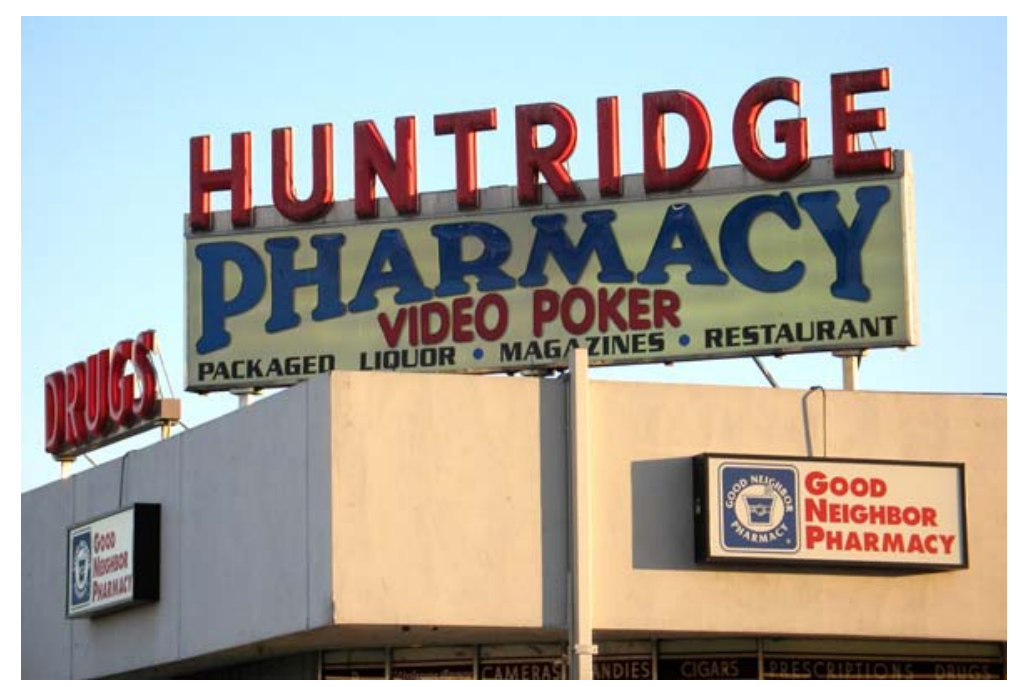

Fig. 1. Pharmacy in North Las Vegas advertises video poker. Photograph by the author. 


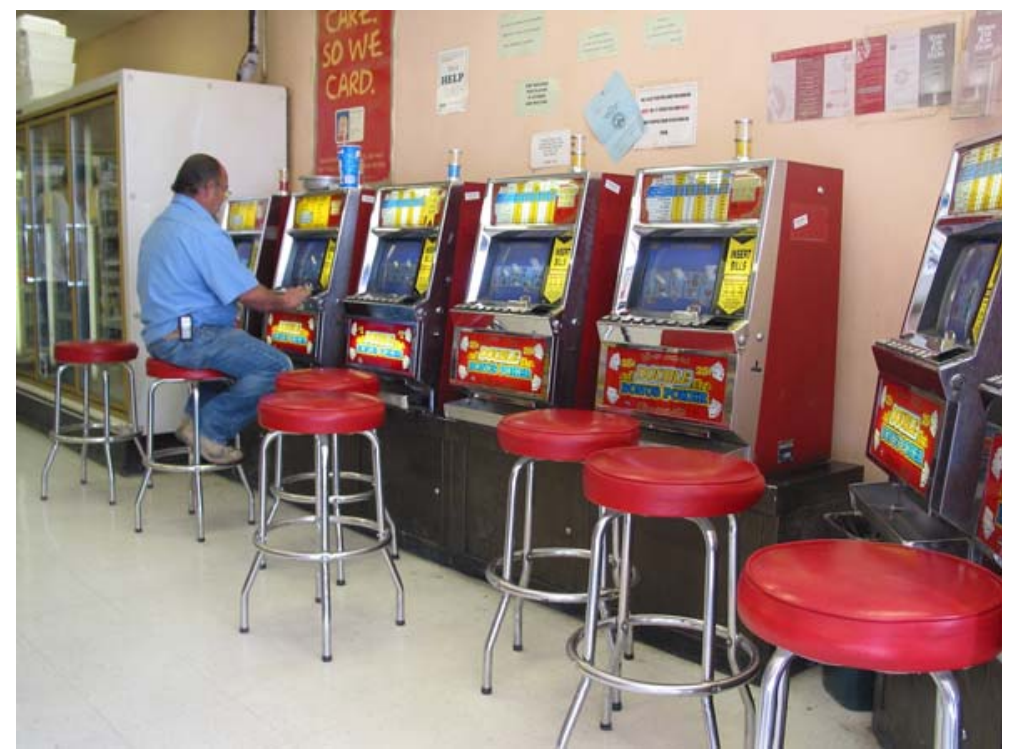

Fig. 2. Photograph by author.

the city. Across town, Trimeridian Problem Gambling Consultants, Incorporated, ${ }^{2}$ the first for-profit gambling clinic in Las Vegas, provides intensive outpatient therapy. In 1998, contracted by Eli-Lily, Trimeridian recruited video poker players to participate in a pharmaceutical trial for Zyprexa, a widely prescribed antipsychotic that researchers hoped might reduce cravings to gamble. "As in many a capitalistic country, the private sector has stepped to the forefront in treatment design and implementation," wrote one of the company's spokespeople (Franklin n.d.). Charter Hospital, a partner in the drug study, housed an inpatient treatment facility for pathological gamblers until the national collapse of its hospital chain, whereupon the facility's director established the nonprofit Problem Gambling Center in a blighted downtown neighborhood. The Center was established with significant financial support from gaming businesses (Berhnard, n.d.). ${ }^{4}$

At the same time that the gaming industry designs entertainment technologies to incite extended consumption, the "recovery industry"-by which I mean a therapeutic complex comprising the purveyors of individual counseling, in-and out-patient therapy groups, self-help groups and literature, and pharmacological aids for the addicted-designs therapeutic technologies that promise to weaken the bind of this consumption and release subjects from its habitual clutch (either by blocking or numbing stimulation at the site of its reception, by arming individuals with the means to resist stimulation, or by providing a less toxic substitute stimulation). As 
Nicholas Rose (1999) notes, technologies of consumption and "psychological technologies, concerned with the care of the soul... are interlinked" (85). In an additive circuit of technological application, solutions to the problems that arise from one set of technologies are sought in another set. ${ }^{5}$ Although the objectives of each industry's products are seemingly at odds - gambling machines work to encourage play, addiction therapeutics to stop it - both gear their interventions around a model of the self as an ever-changing configuration of behavioral potentials responsive to external modulation.

For compulsive gamblers implicated in these interventions, technology functions as a medium for self-destruction as well as self-care. In their engagements with entertainment technologies and therapeutic technologies alike, gamblers seek states of balance: in the case of video gambling, a tensionless state of absence they call the "zone;" in the case of therapeutic applications, an attentive state of presence they characterize as "health." As gamblers attest, it is not simply that their machine play is isomorphic with their therapeutic practices, but rather that a certain complicity and even interchangeability develops between the two, blurring loss of self and recovery of self.

My goal in the following pages is neither to collapse nor to stake out the differences between addiction and health, but rather to illuminate the unexpected resonance of their technologies and techniques, and to ponder what this resonance might indicate about the changing terms, stakes, and challenges of health in the contemporary United States. I draw on research conducted among compulsive machine gamblers in local self-help groups, directed group therapy sessions, and the chat rooms of Internet recovery fora. In these varied therapeutic sites, recovering selves reflexively engage the technical resources of diverse expert systems to formulate provisional models of health. ${ }^{6}$ The questions they pose, the answers they tentatively articulate, and the tensions they raise in their exchanges offer clues to broader shifts in understandings of illness and health.

\section{THE MODULATING SELF}

I've been pondering the nature of addiction and I think we all have the potential for some behavior to become extreme, it's just that most of us have another behavior to counterbalance it. The idea I've been fiddling with - that certain behaviors balance out other behaviors in some complicated way-is an equilibrium concept. Being a chemist and a nuclear scientist, I have a feeling for different kinds of equilibria.

(Rocky, gambler and nuclear chemist) 


\section{N.D. SCHÜLL}

On a Saturday morning in the back room of Trimeridian's office suite, Julian Taber handed out copies of a four-page document to the participants in his group therapy session. The document was a catalog of addicting items to which he alternately referred as the Consumer Lifestyle Index and the Inventory of Appetites. ${ }^{7}$ The items were listed in no apparent order, each followed by boxes to check for "6-12 month use" and "lifetime use" (see Figure 3). The ten of us in attendance proceeded together through the list and marked each weak link in our respective chains of will, adding new items along the way. A vocal young woman proposed that "Spending just for the sake of spending" and "Searching for, buying and collecting certain items" be clustered together with two new categories_- "Shopping for shopping's sake" and "Buying and returning things," compulsive tendencies which she considered to be of the same family but slightly different from the two already included in the index. ${ }^{8}$ Underlining the nonproductive, selfreferential character of addicts' conduct, the therapist suggested that "Buying for the sake of returning" might make a more accurate phrasing of the second habit, and it was added to the list. Half the people in the room, including the anthropologist, gave themselves a check for that behavior. A middle-aged real estate agent came up with "Carbohydrates" and "Vitamins/other health foods," musing that although the first was bad for his body and the second good, he was nevertheless addicted to both. A younger man pointed out that "Video games" and "Internet use" were obvious missing items, and a soft-spoken woman volunteered the less obvious "Taking care of your child," an idea that produced a quiet pause. Everyone agreed that "Self-help"-a blanket category covering tapes, literature,

Cocaine
Heroin
Amphetamine or similar "pep" pills
Morphine or related opium-like drugs
Gambling for money
Marijuana
Pipe, cigar, cigarette, snuff or chewing tobacco
Alcohol, beer, wine, liquor, whiskey, etc.
Barbiturate and similar sedative drugs
Hallucinogenic drugs (LSD, PCP, mescaline, etc.)
Caffeine (tea, coffee, cola beverages, etc.)
Exercise, jogging, playing sports or working out
Seeking and having sex with another person
Seeking and using pornography
Watching television
Talking for talking's sake
Searching for, buying and collecting certain items
Lying (for no good reason)
Aspirin or other non-prescription pain
$\quad$ medications
Controlled (prescription only) pain medications

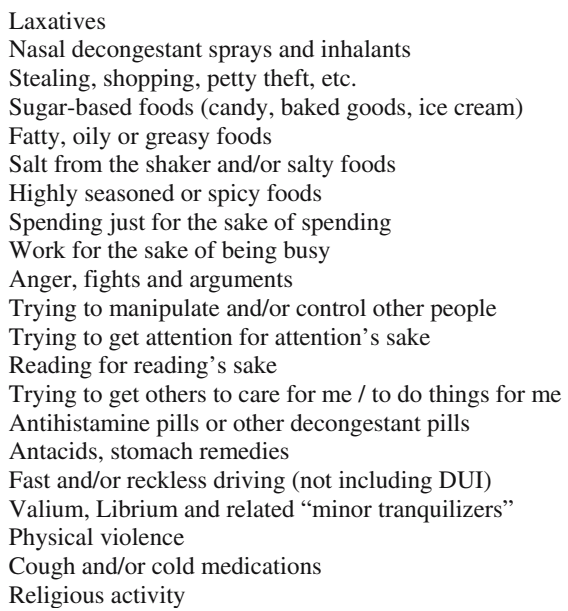

Nasal decongestant sprays and inhalants

Stealing, shopping, petty theft, etc.

Sugar-based foods (candy, baked goods, ice cream) Fatty, oily or greasy foods

y seasoned or spicy foods

Work for the sake of being busy

Trying to manipulate and/or control other people

Trying to get attention for attention's sake

Reading for reading's sake

Trying to get others to care for me / to do things for me

Antihistamine pills or other decongestant pills

Antacids, stomach remedies

Cough and/or cold medications

Religious activity

Fig. 3. Consumer Lifestyle Index/Appetite Inventory (Julian Taber). 
techniques, and self-directed as well as group programs-belonged on the list. At that point it seemed there was nothing left to say, and the collective inventory-taking exercise that had begun an hour earlier came to a close. We stood to stretch, to visit the washroom, to step outside and smoke.

Following that afternoon's session I attempted to extract the key lessons of the exercise we had performed on ourselves. These lessons echoed a broadening conception of addiction that has gained wide cultural circulation over the past decades. ${ }^{9}$ The first lesson, communicated by the number and diversity of items on the list, was that anything can addict. Although no substance or activity was bad in and of itself, any behavior-no matter how necessary, benevolent, or life-enhancing it might be when practiced sparingly or even regularly - could become pathological when practiced in excess, or "for its own sake." One man remarked, "Anything that's overly done is not good for us; if you get excessive with running it's an addiction. Religion too - there are people who just have to go to church all the time and that's an addiction." This lesson was confirmed when participants unanimously voted self-help into the catalog of addicting items, recognizing that this practice was potentially as addictive as the addictions it was designed to control. The second lesson was that anyone can become addicted. A participant in the session commented: "Aren't we all born with addictive tendencies, to some degree? For one person it's shopping, for another person it's cleaning, or working. For me, it's gambling and cigarettes." A new member to the group reflected along the same lines: "I hear a lot of people say how many different kinds of addictions they have; it seems like addiction or compulsion is in everybody - some of us do one thing and some of us do another. Even normal people have addictions." The potential to become addicted was not an aberration, we learned, but something we all carried.

A subcomponent of this second lesson was that individuals were likely to have more than one susceptibility, or, as Taber put it, "a variety of possible dependencies." A local psychologist remarked to me: "Among my patients, co-morbidity is the rule - maybe because I live in Vegas." A form of comorbid subjectivity became apparent to me as I spent time in the city's selfhelp community. Participants in GA meetings frequently expanded the typical self-identification of "compulsive gambler" to "compulsive person" or, even more expansively, "compulsive everything." I heard one man introduce himself this way: "I'm addicted to everything. I'm an addict." Addiction, at the therapeutic sites where I conducted research, was a mercurial condition, unhinged to specific substances and open to a proliferating chain of attachments and substitutions.

These two lessons - that the world is a field of potentially addicting elements and that the human being is a field of potential dependencies - set 
the ground for a third lesson, on how to understand the task of the subject who mediates between these two fields. At the close of the session, therapist Taber concluded, "Addiction is a problem of you governing your own life-not the government." By "govern" Taber did not mean that gamblers should abstain from all potentially addictive activities - an impossible task because this would be to abstain from life - but that they should vigilantly manage themselves. The following text, sent to me some months later by a gambler I met in Taber's group, resonates with his injunction to selfgovern:

At the moment, I am in remission, keeping my illness maintained, contained-just like my son does with his ADHD meds, just like my husband does with his diabetes meds, like my mother in law with her cancer support groups. Like someone with cancer, diabetes, or even the common cold, I MUST take care of myself, I MUST take my medicines. I take my meds every day - counseling, prayer, reading posts, emailing with my fellows, going to meetings, learning about myself, helping my fellows, and even taking a medication for anxiety/compulsive behavior. Now I have the "medicines" to keep me from ever being that sick again.

This passage, riddled with the imperative "must," articulates a code of conduct in which individuals are held accountable to "maintain" and "contain" their conduct by arming themselves with an array of techniques and technologies, all understood under the sign of medication. Medication serves as the means for sustaining a tenuous threshold state that Joseph Dumit (2002b) aptly terms "dependent normality." In this conception, health itself is a state of dependency - not something that can be definitively accomplished or recovered but a balancing act requiring ongoing pharmaceutical modulation. The "pharmaceutical self," as Dumit (2002a) names him, experiences his symptoms "as if he is on bad drugs, too little serotonin perhaps, and in need of good drugs, like an SSRI, to balance the bad ones out and bring both biochemistry and symptoms to proper levels." As Nikolas Rose observes, "The active and responsible citizen must engage in a never-ending monitoring of health" (2003a:58), "a constant process of modulation, adjustment, and improvement" (2003b:430).

Counselors at the Trimeridian clinic arm their clients with behaviormodifying tool-kits that include daily and weekly "craving scales" which requires them to numerically rate the duration, intensity, and frequency of their gambling urges along a range of subjective measures (see Figures 4 and 5). ${ }^{10}$ These scales, "borrowed directly from the neoliberal arsenal of tools with which consumers/clients can plan their own futures and govern their own lives, their consumption, their health, and their risks" (Valverde 1998: 175), encourage individuals to exercise their calculative capacities to manage inner states in a kind of responsible "self-accounting" (Miller 2001: 106). A 


\section{GAMBLING CRAVING SCALE}

1. On the line below, please circle the number that best describes how strong on the average your craving or urge to gamble has been during the past week, with "I" representing no cravings at all and "9" representing extremely strong cravings.

\begin{tabular}{|c|c|c|c|c|c|c|c|c|}
\hline $\begin{array}{c}\text { NO } \\
\text { CRAVING }\end{array}$ & & MILD & & MODERATE & & STRONG & & $\begin{array}{c}\text { EXTREMELY } \\
\text { STRONG }\end{array}$ \\
\hline 1 & 2 & 3 & 4 & 5 & 6 & 7 & 8 & 9 \\
\hline
\end{tabular}

2. On the line below, please circle the number that best describes how strong your worst craving or strongest urge to gambling has been during the past week.

\begin{tabular}{|c|c|c|c|c|c|c|c|c|}
\hline $\begin{array}{c}\text { NO } \\
\text { CRAVING }\end{array}$ & & MILD & & MODERATE & & STRONG & & $\begin{array}{c}\text { EXTREMELY } \\
\text { STRONG }\end{array}$ \\
\hline 1 & 2 & 3 & 4 & 5 & 6 & 7 & 8 & 9 \\
\hline
\end{tabular}

3. On the average, how frequently (how many times per week) have you experienced an urge or craving to gamble during the past week?

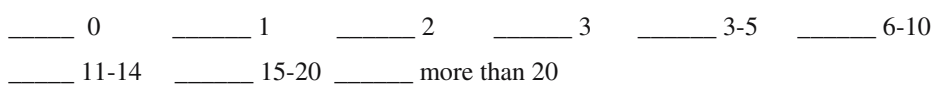

4. On average, how long has the craving or urge to gamble lasted during the past week?

\begin{tabular}{|c|c|c|}
\hline $0-5 \min$ & $6-15 \min$ & $16-20 \mathrm{~min}$ \\
\hline $30-45 \mathrm{~min}$ & $45-60 \mathrm{~min}$ & $1-2$ hours \\
\hline
\end{tabular}
more than 3 hours

5. Overall, do you feel your cravings or urges to gamble are:

\begin{tabular}{|c|c|c|c|c|c|c|c|c|}
\hline $\begin{array}{c}\text { SIGNIFICANTLY } \\
\text { DECREASING }\end{array}$ & $\begin{array}{c}\text { SOMEWHAT } \\
\text { DECREASING }\end{array}$ & $\begin{array}{c}\text { THE } \\
\text { SAME }\end{array}$ & $\begin{array}{c}\text { SOMEWHAT } \\
\text { INCREASING }\end{array}$ & $\begin{array}{c}\text { SIGNIFICANTLY } \\
\text { INCREASING }\end{array}$ \\
\hline 1 & 2 & 3 & 4 & 5 & 6 & 7 & 8 & 9 \\
\hline
\end{tabular}

Fig. 4. Weekly Gambling Craving Scale (Trimeridian Problem Gambling Consultants).

homologous accounting technology appears in the form of a "money management chart" included in a book called "Slot Machine Mania" (Crevelt and Crevelt 1988) (see Figure 6). The author, a gaming industry designer, offers the chart as a way for gamblers to keep an "efficient record" of their own financial behavior-to track their "balance," as it were. As one's subjective and financial balance approaches "zero," one approaches a state we might think of as "consumer health." Similarly, in her work on mood charts as a means of self-regulation, Emily Martin (2004) described how a guest introduced himself to a mood disorder support group, following the protocol that speakers choose a number on a scale from -5 to 5 to 
N.D. SCHÜLL

PG CRAVING SCALE

100mm Visual Analog

$$
" 0 "=\text { Not at all } \quad \text { "100" = Most Ever }
$$

$$
0
$$$$
\text { "I would like to gamble" }
$$

$$
0
$$

"I intend to gamble in the near future"

0 100

"Gambling will make me feel better"

$$
0
$$

"Gambling would get rid of any discomfort I am feeling"

$$
0
$$

"I feel I can control my gambling"

Fig. 5. Pathological Gambling Daily Craving Scale (Trimeridian Problem Gambling Consultants).

indicate their present mood status: "I'm Brad and I guess I must be zero." This self-introduction registers the conception of health as a kind of homeostatic zero state, or as Rocky put it in the epigraph to this section, a kind of "equilibrium concept."11

In what sense do such recovery techniques, borrowed from a more general set of self-making tools, shape an "ethics" (Keane 2002: 159)? In his work on classical and Christian self-care, Michel Foucault (1988) wrote that "technologies of the self permit individuals to effect ... a certain number of operations on their own bodies and souls, thoughts, conduct, and way of being, so as to transform themselves in order to attain a certain state of happiness, purity, wisdom, or immortality" (18). The task of the modulating subject is no longer quite that of the classical ethical formulation, demanding sustained commitment to those operations that promise to bring about virtuous self-transformation and the good life (Foucault 1988, 1990). ${ }^{12}$ Instead, the task is to discern which techniques and technologies 


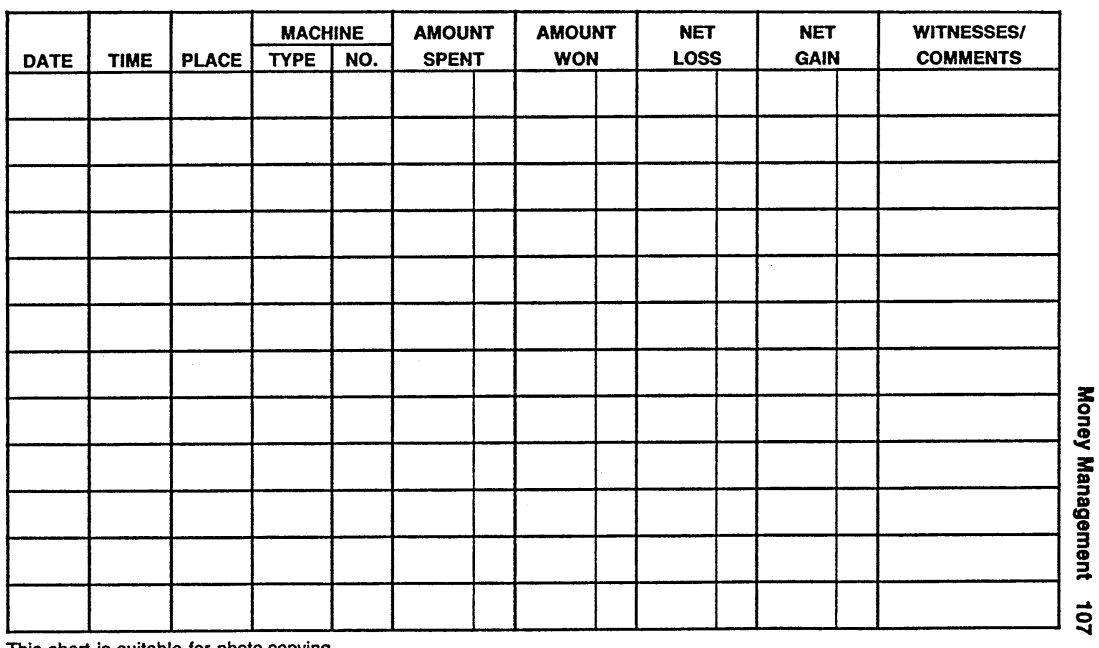

This chart is suitable for photo-copying

Fig. 6. Money Management Chart (Crevelt and Crevelt 1988).

can enable a slight shift in degree or direction or speed of movement so as to neutralize affective excess and restore balance. This is an ever-miniaturizing temporal and gestural economy: an economy of adjustment rather than abstinence; compensation rather than commitment; maintenance rather than transformation. As gamblers demonstrate in the coming pages, the technical repertoire of the modulating self is not hinged to any particular ethical telos, but rather carries over from the domain of self-recovery to the domain of self-loss, and back again.

\section{TECHNIQUES OF SELF-EXIT, TECHNIQUES OF THE SELF}

Game industry technology engineers design machines that facilitate the zone state compulsive gamblers describe, enabling them to forge an insulated, autonomous space of play in which they can set and reset their own bet level, rhythm, and pace. The tempo they establish functions as a form of predictability that structures and regulates their play, promising to hold them in the zone state as long as they hold its rhythm, no matter how fast they go. "The fact that I'm in motion is calming, and kind of mechanical," said Randall, a middle-aged electronics technician. Like tightrope walkers who maintain balance through constant compensatory motion to either side of an upright axis, the balance of the zone is a kind of dynamic or kinetic (rather than static) equilibrium (Bateson 1972: 125), an affective plateaustate they maintain by oscillating with the least possible amplitude around a 


\section{N.D. SCHÜLL}

median of player credit. This movement is autotelic in that its aim is to perpetuate itself rather than to maximize monetary payoff in the climax of a jackpot. ${ }^{13}$ In the economy of the zone, "It's not about winning-it's about continuing to play," said Lola, a young buffet waitress. Winning too much, too soon, or too often disturbs the flow of play, as she describes: "If it's a moderate day - win, lose, win, lose-you keep the same pace. But if you win big at first, it can prevent you from getting into the zone." When credits get too high, or too low, a sense of tension threatens the tensionless state of the zone.

Janet, ${ }^{14}$ a quiet young woman who works in a 99-cent store off the tourist strip, wears thick glasses and a hearing aid. She is constantly anxious because she is ashamed to ask people to repeat themselves when she has not heard them, or to create the impression that she is stupid. She plays video poker every day at the grocery store to gain exit from this predicament. "At the machines you get into a rhythm and go into the zone; the whole world spins around you and you can't hear anything, almost like you're not there," she tells me. Janet has learned that she can enter the zone most efficiently and completely by turning off her hearing aid, or tuning it to "another frequency" while she plays. When she combines video poker and the refreqencing of her hearing aid with the amphetamines her husband deals or the Ritalin her son takes, she achieves this relief even more readily.

It is not unusual for compulsive gamblers to describe the effects of their machine play itself as drug-like. "The machine is like a really fast-working tranquilizer. Playing, it takes two minutes to disappear, to forget, to not feel. It's a wonderful way to alter my reality - an immediate mood shifter," said Randall. Machine play can also shift bodily sensation. Carla, a nurse in her late thirties whom I met at Trimeridian, felt sudden cramps one day while driving down Boulder Highway and pulled into a gas station to gamble. As she began to gamble, she was overcome with a numbness that lasted until her last quarter ran out, whereupon she felt severe pain, looked down, and saw that she was hemorrhaging. "It interferes with the pain receptors or something," she said, speaking of the machine in a pharmaceutical idiom, as an analgesic technology operating at a neurochemical level to block feeling.

A telemarketer named Mollie whom I met at a GA meeting told me: "A very common 'slip' when people read aloud from our book is: 'Sought through prayer and medication' (instead of meditation), which is laughable but truthful, because we have all self-medicated so much." When one recognizes, with Mollie, that machine play and the application of therapeutic technologies are both forms of self-medication, it becomes difficult to parse modes of withdrawal associated with addiction from modes of self-attentive 
therapy associated with health. Mollie approaches the project of self-recovery with the same combinatory drive at play in her self-loss, assembling an arsenal of tools and techniques to bring herself into balance:

Some say I need different meds. Some say I should connect with the Anxiety and Social Phobia message boards. Some people tell me I need God in my life. Others say if I just do the Twelve Steps ${ }^{15}$ I'll be OK. They're all probably right. A combination of group and/or individual therapy, meds, GA, and virtual therapy on the internet, is what counts.

This statement, posted to an online forum for gambling addicts, prompted other gamblers on the forum to share their own therapeutic assemblages. A man called Ron had cobbled together the following techniques to manage the psychological disquiet that drives his addiction:

Meditation - a simple breath-watching exercise - gets the mind-chatter under control for about two hours. Same with exercise. I need a large endorphin-rush, so I play handball now and then. I also lift weights and swim at a local gym. That gym also offers yoga classes. All of these help. Also no access to extra money-for me, the credit cards that only work at the hardware store, the gas pump, the local Costco, are safest.

Meditation, diverse forms of exercise, and limited-access credit cards are components of Ron's custom-tailored assemblage of self-care strategies, designed to bring his endorphins, mind-chatter, body, and will into a state of subjective equilibrium that keeps him out of the zone and engaged in worldly circuits. The micro-techniques of the recovering subject, like those of the addict, work to quell perturbations in the system and "zero out" excess affect.

Online and at GA meetings, gamblers exchange advice on the different medications they have been prescribed-Xanax, Neurontin, Paxil, Zoloft, Prozac, Percoset, Ritalin. ${ }^{16}$ "It sounds like you should try adding an antianxiety medication to your recovery," writes one woman; "If I ever get medical insurance, I think I need Neurontin," writes another. Rocky told me: "I keep a meticulous record of the medications I take-I've gotten to the point where I can cut my Xanax dosage in half and take it every four hours." Notwithstanding the regulatory control Rocky exercises over his ingestion of medication, its acquisition carries risks he cannot quite manage: "Every time I go fill my prescriptions for Prozac and Xanax I run the risk of getting stuck for hours at the gambling machines in the drugstore." Not only do the means of addiction and the means of recovery function similarly as modes of self-medication - they are also physically proximate, available in the very same consumer spaces. ${ }^{17}$ 


\section{N.D. SCHÜLL}

Patsy, a middle-aged welfare officer, described to me how Paxil worked to "even out" her moods and regulate the bodily pains she experienced as a result of constant anxiety about work: "Before Paxil, I would medicate myself with machines. But after playing I would have strange pains in my jaw and my ears, and my menstrual cycle and appetite were irregular. Paxil is wonderful, it's an absolute miracle. I can feel it go to my brain and stop the anxiety from forming, and now all the pains have stopped.' In Patsy's narrative, her machine play began as a form of medication to treat her emotional and bodily disequilibrium; although machines alleviated it to some extent, they had the effect of aggravating and even producing new imbalances and irregularities, amplifying the need for more medicine. She went on to tell me that Paxil itself had ill effects, flattening her mood to a point where she gambled without guilt and was able to more easily access the zone state: "On the drugs, it didn't take as long to get there." For compulsive gamblers, pharmaceuticals tend to function like Derrida's (1981) pharmakon: "The pharmakon can never be simply beneficial ... what is supposed to produce the positive and eliminate the negative does nothing but displace and at the same time multiply the effects of the negative, leading the lack that was its cause to proliferate" (100).

Mollie's experience with pharmaceuticals gives further illustration of their implication in the circuitous pathway of addictive drives. Mollie, who walks with a cane and wears a full prosthetic leg, describes video poker as a mechanism for escaping from her body. Yet play can also stimulate pleasurable bodily sensations: "I would have what you might call mini-orgasms at the machines. It was kind of a tightness but just very small, an exciting kind of release. It would happen when I got certain card combinations." Within the insulated space of play, Mollie is able to experience her body in a way she otherwise finds difficult. She occasionally has sex with her husband, but this for her is "strictly mechanical." She takes the pharmaceutical Zoloft in part because it prevents her from having orgasms with him, sensations that leave her feeling "too close," dangerously exposed. For Mollie, technologies can act both to sensitize and anesthetize: Machine play disconnects yet also stimulates; Zoloft, prescribed to help her abide with worldly ties, in fact works along with the machine to keep over-stimulating human engagements at bay.

Beyond the evident isomorphism that exists between the self-administration of pharmaceutical drugs and of machine play, it becomes clear that the two are in communication and sometimes work in tandem: drugs that have been prescribed to dampen cravings for machine play come to function as intensifiers of its effects. The therapeutic and the addictive collude. ${ }^{18}$ Ann, a recently divorced small business owner in her late fifties, was 
prescribed Xanax to counteract the anxiety that she sought to neutralize with her machine play. Almost immediately, the drug was incorporated into her play:

I'd get so anxious when I was playing machines, I'd have panic attacks. My doctor prescribed Xanax and I never felt so good in my life. I was hooked for eight years. I'd take them while I was gambling. I'd feel the panic if I'd start losing, and also if I'd win - it was like an overload of excitement - and I'd pop two Xanax, or three, and it would calm me right down. I was taking four a day, I was supposed to be taking one. The doctor never knew about the gambling and how I used the pills with it. I'd just have him call in my prescription. If my prescription ran out, I knew somebody who lived in North Las Vegas who could buy them for one or two dollars a pill.

Ann's story, by the end of which she comes to illegally obtain drugs first prescribed by a doctor, illustrates what Anne Lovell (2006) has called "pharmaceutical leakage," whereby a prescription pharmaceutical migrates from a treatment context to "an informal, illicit network (the drug economy)" (138). As Ann narrates it, the calming properties of the medication Xanax are activated by an overload of excitement produced by gambling machines; as the medication modulates the ebb and flow of her panic, it becomes part of the circuit of play. The activity of machine gambling, in turn, modulates the calming effect of Xanax, becoming part of the pharmacological process. An unexpected interdependence forms between Xanax and video poker.

After telling how a prescription drug became complicit in the very "escape mechanisms" it was meant to treat, Ann tells how she counteracted this poisonous mixture with still other "medicines." The scene takes place, perhaps not surprisingly, in a pharmacy:

Now I'm off the Xanax, and trying to stop gambling. The other day I had to pick up my parents' prescriptions. I pulled into a Savon drug store and I felt so afraid that I would gamble. It wasn't like they needed an aspirin-my parents are both heart patients and these were major prescriptions that I needed to fill, but I just couldn't go in. I sat in my car and meditated. Then I used my serenity prayer as a great tool. I said, God, grant me the serenity to accept the things I cannot change. I thought, Now what can't I change? I can't change that they need their medicine. The next verse is What can I change? I can change me not gambling. I asked my higher power just to please guide me through, to give me the strength to just go in there and take care of my business, and I did. I walked in there, directly past the poker machines to the pharmacy. I left my wallet in the car, just took a check and my car keys. I went back, unlocked the car, locked the car door behind me. It was a big hurdle for me.

Ann, well-practiced at mixing machines and medications to achieve the detached flow of the zone state, puts her expertise to work in the service of attentive self-care, deploying a combination of meditation and therapeutic mantras to hold herself in check. 


\section{N.D. SCHÜLL}

Maria is a gambler for whom not only medication but meditation has become implicated in her addiction, bringing us full circle back to the humorous GA slip that compulsive gamblers make while reading aloud, in which they transpose the two words. She began gambling to dull the distress of a divorce and an unwanted pregnancy; when she attempted to stop, she had panic attacks. She assumed these were part of her "withdrawal from the machines," but when they did not subside she visited a doctor. He offered pharmaceutical treatments but Maria "refused to be medicated," fearing she would become addicted to the drugs as she had been to the machines: "Medication was liable to become part of the problem," she told me. Even nonpharmaceutical forms of therapy struck her as dangerous because of the way that she had "used" them during her addiction:

One recovery step says Seek through prayer and meditation to improve your conscious contact with God as you understand him. Spirituality plays such a big role in the recovery steps but my dilemma is that gambling itself was linked to spirituality from the start. I would meditate at night to try to see the cards that were going to come up on the machine the next day. It was never an out-of-body experience, but I'd be flying and all of a sudden I'd be somewhere in front of a machine and it was like a vision, I'd see a certain card combination. So I was afraid to pray and meditate during my recovery because I made a connection to what I had done when I gambled. I'd think, I'd better not do that step...

In the very act of exercising therapeutic practices, Maria runs the risk of addiction.

Compulsive machine gamblers living in Las Vegas are particularly attuned to the double bind of the pharmakon as Derrida described it - the impossibility of seeking remedy without constantly encountering poison. A participant in an online forum for recovering gamblers discloses the ambivalent, pharmakon-like functioning of her computer: "I spent most of the last several months of my gambling in total isolation in front of the computer. That is where I reached my bottom and that is why the online recovery sites are so important to me." The computer co-functions as a vehicle for addiction and recovery, as it does for another gambler who posted on the same site.

I tried filtering out gambling sites using key words such as gamble, gambler etc., but that prevented access to online recovery sites such as this one which have become so very important to me and my own personal recovery. I pray that you too will find the strength that you need to uninstall all of those online casinos and replace them with recovery sites.

Compulsive gamblers' wish to filter out the toxic from the vital, to remove links to illness while preserving links to cure, seems destined to fail. As in the Appetite Inventory exercise recounted earlier, with each new addition to the 
index of potential dangers participants rehearse their wish to separate negative from positive, unhealthy from healthy. Yet the final lesson of the exercise - clinched by the addition of therapy itself to the list of perilous conduct - is that the two cannot be definitively distinguished in a context where addiction and the means to control addiction run on a continuous circuit.

\section{CONCLUSION: TERRY, REVISITED}

The last time I visited Terry, she looked around her apartment and catalogued recent developments in her life by way of a technological inventory. She had a new oxygen tank from which she didn't dare venture far-it was such an effort to drag around that she wasn't going out much. The car she had managed to buy had been stolen, making it difficult to refill her medical prescriptions. Her microwave, on which she "had become quite dependent," had quit a week earlier. She didn't own a computer, she said, only a broken typewriter. She had a radio but it had stopped working. She didn't have the money to replace these appliances but she was "learning to adjust." Only one of her three televisions worked, somewhat. "If it goes out" - and she wouldn't be surprised if it did-she would "have to learn to get along without it."

Living in a world where potentially addicting elements are tactical components in the task of self-care and palliative elements are potentially addicting, gamblers in recovery are challenged to configure and reconfigure their technological interactions to maintain balance. What kind of relationship might this work of technological maintenance bear to the broader political, social, and economic context? A number of scholars have described the recovering self as a kind of Homo economicus who fulfills the demand of neoliberal government for "active individuals seeking to 'enterprise themselves,' to maximize their quality of life through acts of choice" (Rose 1996: 57; see also Miller 2001). Yet recovering compulsive gamblers model a somewhat different kind of self - not a consumer sovereign who masterfully pursues a pristine, coherent, and unconflicted set of desires, but a subject whose desires constantly shift in response to environmental feedback, and who constantly recalibrates action in relation to those shifting desires - modulating action not to maximize but to maintain. ${ }^{19}$

Writing against the assumption that individuals are naturally motivated to maximize particular variables - wealth, property, et cetera-Gregory Bateson (1972) described the self as a cybernetically organized system that self-corrects against disturbance (435). He famously wrote of the Balinese as 
"striving to maintain a dynamic equilibrium or steady state," valuing "balance and such movement as will conduce to balance" (125). Borrowing from the vocabulary of communications engineering, he characterized their social system as "degenerative." Bateson understood addiction-and capitalism itself - as a "regenerative" form of self-correction in which engagement with an external element "provides a partial and subjective short cut to a more correct state of mind" (309). "Over time," he wrote, "the system becomes dependent upon the continued presence of that original external impact whose immediate effects were neutralized by the first order homeostasis" (448). Regenerative systems, "if provided with the necessary energy sources and if external factors permit, will clearly operate at a greater and greater rate or intensity" (109). ${ }^{20}$

Within Bateson's diagnostic framework, the case of compulsive machine gambling appears to be one in which individuals' self-correcting tendencies serve as the modus operandi of a larger, regenerative social system. If one accepts that individuals have always modulated their internal states to maintain balance, and that they have always employed techniques and technologies to do so, what seems to be unique about the present moment is the intensified business of this modulation - the ways in which the entertainment industry and the recovery industry set the value of homeostasis - or in cybernetic terms, 'encode the ideal.' As Colin Gordon (1991) reminds us: "Whereas Homo economicus originally meant that subject the springs of whose activity must remain forever untouchable by government, the American neo-liberal Homo economicus is manipulable man, man who is perpetually responsive to modifications in his environment" (43). Contemporary power relations, Gilles Deleuze (1992) has argued, are characterized by continuous, diffuse modulation. Both in health and in illness, the neoliberal self — whom we might call Homo addictus - is at once self-modulating and modulated from without.

As I indicated at the start of this essay, my aim is not to claim that states of health and illness are becoming the same, nor to stake out their differences. Rather, my concern has been to identify and explore a conception of the self, a style of conduct, and a set of applications common to both domains, and to reflect on the challenges that the fact of this shared techne might pose to contemporary projects of self-care. Compulsive gamblers' quest for a state of health that is qualitatively different from a state of dependency may be so elusive in part because this quest shares the homeostatic logic and modulatory practices of their addiction and depends on the same array of techniques and technologies.

The equilibrating circuit of compulsion and care in which Las Vegas machine gamblers are stuck is part of a larger context in which everyday 
managed subjectivity and collective life run not only on risk-taking and maximization, but also on reflex and maintenance. Although these unenterprising features would seem to depart from the rhetorical content of neoliberal norms, I understand them as more than the "negative index" or symptomatic failure of the dominant form of subjectivity, the "constitutive outside to domains of health" (Keane 2002: 8), ${ }^{21}$ or as evidence that addiction is a state of social exclusion, as Nikolas Rose (2003b) proposes. He writes of addiction therapies: "The aim is to enable the individual to reenter the circuits of everyday life, where he or she will re-engage with the cybernetics of control built into education, employment, consumption, and leisure" (431). The case of compulsive machine gamblers suggests that addicts are not necessarily outside of the "circuits of everyday life" and the "cybernetics of control" that regulate these circuits. Although they do not exactly manage, as scripts for the ideal neoliberal self would have it, to subtly and consistently finesse their movement toward a golden mean of selfmaximization, nor does their movement mark the erratic, pathological flipside to the healthy self. The predicament of compulsive machine gamblers offers clues to aspects of normative neoliberal subjectivity that analyses framed solely on models of entrepreneurial selfhood miss.

\section{ACKNOWLEDGMENTS}

This article was completed during my time as a Robert Wood Johnson Health and Society Scholar at Columbia University. My analysis benefited from the generous and excellent feedback of Stephen Rosenberg, Andrew Lakoff, Johan Lindquist, Scott Vrecko, Jonathan Tresch, Vincent Crapanzano, Aaron Nathan, Brad Lewis, and two anonymous reviewers, as well as from Emily Martin, Rayna Rapp, and the participants in their Science Studies Working Group at New York University.

\section{NOTES}

1. This article draws on a chapter from a larger ethnographic study on the links between novel forms of technological interface and the changing ground of human experience (Schüll n.d.). In the book I argue that compulsive gamblers' drive for "machine escape," as they call it, is complexly related to cultural anxieties about entrepreneurial selfhood.

2. Trimeridian Problem Gambling Consultants, conceived in 1997, was the first for-profit gambling clinic in Las Vegas. Investors believed there was a profit to be made if insurance companies could be convinced that the pathological gambling diagnosis - which appeared in 1980 in the American Psychological Association's Diagnostic and Statistical Manual of Psychiatric Disorders - warranted coverage. The 


\section{N.D. SCHÜLL}

process of acceptance has been slow, and by the time of the submission of this article the venture had closed its Las Vegas branch. "It's hard to make money treating problem gamblers who often can't pay for services," said a member of the advisory board (quoted in Benston 2003).

3. Although Zyprexa (Olanzapine) was not shown to reduce gambling behavior among video poker addicts and the results of the study were never published, Trimeridian accomplished its chief aim of proving to a major drug company (Eli Lilly) that it could run a competent drug trial.

4. The gaming industry is particularly likely to fund research and treatment ventures that endorse a model of addiction as the manifestation of an innate disposition. For instance, the industry-funded and industry-led National Center for Responsible Gambling (NCRG), a branch of the American Gaming Association (which represents the commercial casino entertainment industry), was founded on the premise that gambling should be unregulated because the vast majority of "normal" people are not at risk for developing a gambling problem. In the interest of developing medications for abnormal individuals, the NCRG "is committed to funding research that someday will identify the risk factors for gambling disorders and determine methods for not only treating the disorder but preventing it, much as physicians can identify patients at risk from cardiovascular disease long before a heart attack." A historical precedent for this tactic of deflecting blame via medicalization is the alcohol industry's funding of research on the disease model of alcoholism in the wake of prohibition.

5. I use the word technology broadly, to describe the purposive harnessing of mechanical devices, techniques, and forms of knowledge. As Weber conceived it, technology is "the problem, given a certain end, of choosing the appropriate means" (Weber 1978:67). Although gamblers' applications lack the systematicity that technology typically implies, the word evokes the striving toward systematicity that characterizes their attempts to assemble an array of devices and techniques to regulate their affective states.

6. The term health as it appears throughout this article refers not to a normative conception of what health is or should be, but to something that is in formation, provisional, and undecided - both as a concept and as a state. I approach health as an object of reflection in the sense that "reflexive modernization" specifies the critical questioning practices of modern subjects, both in domains of expertise and in relation to the self (Beck et al. 1994).

7. The handout, authored by Taber (2001) some years back, had been inspired by "a need to take an inventory of all addictive behaviors." His use of the word "inventory" references both the tradition of "moral inventory" in Alcoholics Anonymous and the financial inventory as a means of "taking stock" of one's worth. Peter Miller (2001) has described how the inculcation of management accounting practices has come to extend to the subjective domains of life, such that subjects deploy their calculative capacities to manage inner states in a kind of responsible "self-accounting" (see also Martin 2004).

8. In a volume entitled I Shop Therefore I Am: Compulsive Buying and the Search for Self (Benson 2000), contributors similarly distinguish between disorders of spending and disorders of buying, among other forms of pathological shopping.

9. As Eve Sedgwick (1992:584) notes, during the first two-thirds of the 20th century the attribution of addiction was extended to a wider and wider range of drugs, and more recently, to all forms of human behavior (see also Berridge and Edwards 1981; Brodie and Redfield 2002). In recent decades, more than 200 self-help groups modeled on Alcoholic Anonymous have formed to help those who believe they are addicted to such activities as shopping, watching TV, exercising, eating, 
using computers, and having sex; a group has even formed to help those addicted to self-help groups. The idea of addiction as a liability continuous with normative human propensities has a correlate in contemporary neuroscience, where dependency is coming to be understood not as a pathological condition but as a potential all humans possess. This scientific normalization of addiction proposes that drugs and certain activities addict because they stimulate or "hijack" the same reward pathways as survival-linked behavior like sex, eating, and the formation of attachments to people and places (Bozarth 1990; Shaffer 1996; Tammik 1997). As Nikolas Rose (2003b) argues, there has been a "mutation in the logic of the norm" such that addiction no longer carries the moral weight of deviancy but, rather, is understood as an error in neurochemical machinery that can be corrected through "individually tailored behavioral and pharmacological" means (439).

10. At the clinic, a battery of testing and diagnostic instruments was administered to compile a dossier for each patient that could be used to code, evaluate, and manage their behavior. The dossier comprised the Human Behavior Questionnaire, the Addiction Severity Index, the Family Environment Scale, the Barratt Impulsivity Scale, the State-Trait Anxiety Inventory, the Beck Depression Inventory, the Dissociative Experiences Scale, and a variety of gambling-specific testing instruments.

11. As a gambler and a scientist, Rocky's articulate reflections on the concept of equilibrium translate his fellow gamblers' discussion of terms like "balance" and "evening out." The term evokes a rich set of expert meanings, from thermodynamics in physics, to innovations in economics such as the Nash equilibrium, to cybernetics, to psychoanalytic conceptions of the way an organism's "reflex apparatus" works to diminish excitation caused by the unsettling stimulation of external events, restoring a state of rest (Freud 1961). The fact that all of these ideas are at play in the term makes it useful for my analysis of a still emerging notion of health.

12. Here I mean ethics in the philosophical sense of "reflection on the problem of how one should live" (Ong and Collier 2005:8). For further discussion of the way in which the classical ethical question of "how to live" is re-posed in the context of contemporary technologies, see Collier and Lakoff"s (2005) discussion of "regimes of living" (see also Biehl et al. 2001; Biehl 2004; Fischer 1999, 2001; Rabinow 1996, 1999).

13. Mihaly Csziksentmihaly (1990) employs the word "autotelic" to describe the psychological state of "flow." Gregory Bateson (1972), describing Balinesian culture, writes that "activity, rather than being purposive, i.e. aimed at some deferred goal, is valued for itself" (117).

14. The dominant narratives in this section belong to women, in part because my project at the time of the fieldwork was conceived as a study of female gamblers and the forms of embodiment and disembodiment they experienced in relation to video gambling technologies. Although the gender of machine play is rapidly shifting, the profile of the average video gambler in Las Vegas today is a 35-year-old woman with two children. Some of the gamblers with whom I spoke suggested that women more readily gravitate toward machine interactions because they are more accustomed than men to taking themselves, and being taken, as bodily objects. Others suggested that women, who are disproportionately represented in the service sector, seek forms of escape that allow them relief from human interaction. Still others pointed to women's unique historical relationship to domestic technological appliances and, more specifically, to slot machines - the product of an incipient gambling industry's attempt to occupy them while their male companions played table games.

15. "Twelve Step" programs require recovering addicts to take certain steps to overcome their addictions. The first step, for example, is "to admit one has a problem." 
16. The generic names for these medications are alprazolam (Xanax), gabapentin (Neurontin), paroxetine (Paxil), sertraline (Zoloft), fluoxetine (Prozac), acetaminophen and oxycodone (Percoset), and methylphenidate (Ritalin).

17. The complicity between addiction and health was made material by Kathy Harris, whose company, the Fitness Gaming Corporation, creates hybrid gamblingexercise machines called the Pedal ' $\mathrm{n}$ Play Cycle fitness bike and the Money Mill treadmill. The games are designed so that one cannot gamble unless one pedals or runs, and vice versa. "Even if you lose at gaming you win at having a "healthful workout," her advertisement states. There are two meters on the machines-one measures gaming credits and the other measures calories burned. As Harris told me in an interview, on a trip to Atlantic City she had felt pulled by two imperatives: "Working out in the health club, I felt like I should be gambling; gambling in the casino, I felt like I should work out. I thought, "They need slots in the health club! I'm going to invent a machine." "The new market coming in," Harris predicts, "will ask for gyms, not cigarettes or alcohol: they're fit conscious. There's a sedentary side to gambling, why not just add health?"

18. Philippe Bourgois (2000) provides ethnographic evidence that methadone patients "mix" the drug with a range of others, including "cocaine, wine, prescription pills, and even heroin" (170): "by strategically varying, supplementing, or destabilizing the effects of their dose with poly-drug consumption, methadone addicts can augment the otherwise marginal or only ambiguously pleasurable effects of methadone" (180; see also Lovell 2006: 153).

19. Although maximization (in its neoclassical economic formulation) is a kind of modulation - in which action is recalibrated relative to the immediate aim of utility - in most economic formulations maximization is assumed to follow a model of rationality in which action stops at an optimal point, defined as the point at which there would be a cost to not investing in another direction; alternatively, the defining attribute of the addict is that he or she does not stop, overshooting the optimal point as defined within the framework of utility maximization.

20. In Bateson's (1972) ecological view, degenerative systems are more in tune with the "mammalian value scale" than regenerative systems, in that animals do not maximize any one physiological variable but seek "to maintain supply of each within tolerable limits. Too much may be as harmful as too little." (122). Here, health is defined as nonmaximizing balance. "Curiously," he writes, "it is yet possible for these creatures to be put into contexts in which they will strive to maximize one or a few simple variables (money, prestige, power, etc)" (123). While degenerative systems work through error-activated, self-correcting circuits to hold a state constant, regenerative systems work through positive feedback loops that cause a "runaway effect," requiring the imposition of degenerative, governing loops to check their maximizing tendencies (447).

21. Addiction holds an ambivalent place in academic treatments. At times, it stands as the constitutive flipside or "negative index" of modernity, pathologizing the predicament of the normative subject of late capitalism (Derrida 1993, 1981; Keane 2002: 8; Melley 2002: 38; Ronell 1992; Sedgwick 1992; Seltzer 1993); at other times, the addict defines that subject: "One can only be a modern subject by running the risk of addiction" (Brodie and Redfield 2002:15). The "autodestructive" tendencies performed in addiction are taken by some as tendencies immanent to modernity itself, which is not only about reflexivity but about reflex (Beck et al. 1994). Zygmunt Bauman (1991) has claimed that the all-night poker addict, rather than the probabilistic risk taker, defines modernity. 


\section{MACHINES, MEDICATION, MODULATION}

\section{REFERENCES}

Bateson, Gregory

1972 Steps to an Ecology of the Mind. New York: Ballantine.

Bauman, Zygmunt

1991 Modernity and Ambivalence. Oxford: Polity.

Beck, Ulrich, Anthony Giddens, and Scott Lash

1994 Reflexive Modernization: Politics, Tradition, and Aesthetics in the Modern Social Order. Stanford, CA: Stanford University Press.

Benson, April Lane, ed.

2000 I Shop, Therefore I Am: Compulsive Buying and the Search for Self. Northvale, NJ: Jason Aronson.

Benston, Liz

2003 VA Offers Gambling Addicts Treatment. Las Vegas Sun. September 24. Electronic document, http:// www.lasvegassun.com/sunbin/stories/text/2003/ sep/24/515659794.htm, accessed September 30, 2003.

Bernhard, B. J.

N.d. Problem Gambling and Treatment in Nevada. Report. Available at: http:// www.hr.state.nv.us/GMU/Reports/Gambling-Addiction.doc.

Berridge, Virginia, and Griffith Edwards

1981 Opium and the People: Opiate Use in Nineteenth Century England. London: St. Martin's Press.

Biehl, João

2004 Life of the Mind: The Interface of Psychopharmaceuticals, Domestic Economies, and Social Abandonment. American Ethnologist 31(4): 475-496.

Biehl, João, with Denise Cuotinho and Ana Luzia Outeiro

2001 Technology and Affect: HIV/Aids Testing in Brazil. Culture, Medicine and Psychiatry 25(1):87-129.

Bourgois, Philippe

2000 Disciplining Addictions: The Bio-Politics of Methadone and Heroin in the United States. Culture, Medicine and Psychiatry 24: 165-195.

Bozarth, Michael

1990 Drug Addiction as a Psychobiological Process. In Addiction Controversies. D. Warburton, ed., pp. 112-134. London: Harwood Academic.

Brodie, Janet Farrell, and Marc Redfield, eds.

2002 High Anxieties: Cultural Studies in Addiction. Berkeley: University of California Press.

Collier, Stephen, and Andrew Lakoff

2005 On Regimes of Living. In Global Assemblages: Technology, Politics, and Ethics as Anthropological Problems. A. Ong and S.J. Collier, eds., pp. 22-39. Malden, MA: Blackwell.

Crevelt, Dwight, and Louise Crevelt

1988 Slot Machine. Mania: Gollehon Press.

Csikszentmihalyi, Mihaly

1990 Flow: The Psychology of Optimal Experience. New York: Harper Perennial.

Deleuze, Gilles

1992 Postscript on the Societies of Control. October 59: 3-7.

Derrida, Jacques

1981 Plato's Pharmacy. In Dissemination. B. Johnson, ed., pp. 61-171. Chicago: University of Chicago Press.

1993 The Rhetoric of Drugs. Differences 5: 1-25. 


\section{N.D. SCHÜLL}

Dumit, Joseph

2002a Drugs for Life. Molecular Interventions 2: 124-127.

2002b The Next New You: Prescribing Ethics for Pharmaceutical Selves. Presented at American Anthropological Association, New Orleans, LA.

Fischer, Michael

1999 Worlding Cyberspace: Toward a Critical Ethnography in Time, Space, and Theory. In Critical Anthropology Now: Unexpected Contexts, Shifting Constituencies, Changing Agendas. G.E. Marcus, ed., pp. 245-304. Santa Fe, NM: School of American Research Press.

2001 Emergent Forms of Life, Ethical Plateux, Risk Society and Deep Plays: Technoscience and Social Critique. Paper delivered at the Society for the Social Studies of Science Annual Meeting, Cambridge, Boston.

Foucault, Michel

1988 Technologies of the Self. In Technologies of the Self: A Seminar with Michel Foucault. Luther H. Martin, Huck Gutman and Patrick H. Hutton, eds., pp. 16-49. Amherst: University of Massachusetts Press.

1990 The History of Sexuality, Volume 3: The Care of the Self. New York: Vintage Books.

Franklin, Joanna

N.d. Problem and Pathological Gambling: A View from the States. Available at: http://www.responsiblegambling.org/articles/Problem_and_Pathological__Gambling_A_view_from_the_States.pdf.

Freud, Sigmund

1961 Beyond the Pleasure Principle. New York: WW. Norton and Co.

Gordon, Colin

1991 Governmental Rationality: An Introduction. In The Foucault Effect: Studies in Governmentality. C. Gordon, G. Burchell and P. Miller, eds., pp.

Keane, Helen 1-52. Chicago: University of Chicago Press.

2002 What's Wrong with Addiction?. New York: University Press.

Lovell, Anne M.

2006 Addiction Markets: The Case of High-Dose Buprenorphine in France. In Global Pharmaceuticals: Ethics, Markets, Practices. Adriana Petryna, Andrew Lakoff and Arthur Kleinman, eds., pp. 136-170. Durham: Duke University Press.

Martin, Emily

2004 Taking the Measure of Moods. Presented at Society for Social Studies of Science annual meeting, Paris, August, 2004.

Melley, Timothy

2002 A Terminal Case: William Borroughs and the Logic of Addiction. In High Anxieties: Cultural Studies in Addiction. J.F. Brodie and Marc Redfield, eds., pp. 38-61. Berkeley: University of California.

Miller, Peter

2001 Governing by Numbers: Why Calculative Practices Matter. Social Research 68(2): 379-396.

Ong, Aihwa, and Stephen J. Collier

2005 Introduction. In Global Assemblages: Technology, Politics, and Ethics as Anthropological Problems. pp. 3-21. Malden, MA: Blackwell.

Rabinow, Paul

1996 Essays on the Anthropology of Reason. Princeton, NJ: Princeton University Press.

1999 French DNA: Trouble in Purgatory. Chicago: University of Chicago Press. 
Ronell, Avital

1992 Crack Wars: Literature, Addiction, Mania. Lincoln: University of Nebraska.

Rose, Nikolas

1996 Governing "Advanced" Liberal Democracies. In Foucault and Political Reason. A. Barry, T. Osborne and N. Rose, eds., pp. 37-64. London: UCL Press.

1999 Powers of Freedom: Reframing Political Thought. Cambridge: Cambridge University Press.

2003a Neurorochemical Selves. Society 41(1): 46-59.

2003b The Neurochemical Self and Its Anomalies. In Risk and Morality. R.V. Ericson and A. Doyle, eds., pp. vi-461. Toronto: University of Toronto Press.

Schüll, Natasha

2005 Digital Gambling: The Coincidence of Desire and Design. Theme issue, "Cultural Production in a Digital Age." Annals of the American Academy of Political and Social Science 597: 65-81.

N.d. Machine Life: Control and Compulsion in Las Vegas. Unpublished ms.

Sedgwick, Eve

1992 Epidemics of the Will. In Incorporations.. J. Crary and Stanley Kwinter, eds., pp. 582-595. New York: Zone Books.

Seltzer, Mark

1993 Serial Killers (I). Differences 5(1): 92-128.

Shaffer, Howard J.

1996 Understanding the Means and Objects of Addiction: Technology, the Internet, and Gambling. Journal of Gambling Studies 12(4): 461-469.

Taber, Julian Ingersoll

2001 In the Shadow of Chance: The Pathological Gambler. Reno: University of Nevada.

Tammik, Tiit

1997 Psychosocial Challenges of Responsible Gambling. Presented at the 10th International Conference on Gambling and Risk-Taking, Montreal.

Valverde, Mariana

1998 Diseases of the Will: Alcohol and the Dilemmas of Freedom. Cambridge: Cambridge University Press.

Volberg Rachel

2001 Gambling and Problem Gambling in Nevada: Report to the Nevada Department of Human Resources. Gremlin Research, Ltd.

Weber, Max

1978 Economy and Society: An Outline of Interpretive Sociology. Berkeley: University of California Press.

NATASHA DOW SCHÜLL

Program in Science, Technology, and Society

Massachusetts Institute of Technology

Building E51-185,

77 Massachusetts Avenue

Cambridge, MA 02139

USA

E-mail: schull@mit.edu 